(2) Open Access Full Text Article

ORIGINAL RESEARCH

\title{
Insomnia medication use and the probability of an accidental event in an older adult population
}

\author{
This article was published in the following Dove Press journal: \\ Drug, Healthcare and Patient Safety \\ II November 2010 \\ Number of times this article has been viewed
}

\begin{abstract}
Alon Y Avidan'
Liisa A Palmer ${ }^{2}$

Justin F Doan ${ }^{3}$

Robert W Baran ${ }^{3}$

'UCLA Department of Neurology, Los Angeles, CA, USA; ${ }^{2}$ Thomson Reuters, Washington, DC, USA; ${ }^{3}$ Takeda Global Research and Development Center, Deerfield, IL, USA
\end{abstract}

Objective: This study examined the risk of accidental events in older adults prescribed a sedating antidepressant, long-acting benzodiazepine, short-acting benzodiazepine, and nonbenzodiazepine, relative to a reference group (selective melatonin receptor agonist).

Methods: This was a retrospective cohort analysis of older adults ( $\geq 65$ years) with newly initiated pharmacological treatment of insomnia. Data were collected from the Thomson MarketScan ${ }^{\circledR}$ Medicare Supplemental and Coordination of Benefits databases (January 1, 2000, through June 30, 2006). Probit models were used to evaluate the probability of an accidental event.

Results: Data were analyzed for 445,329 patients. Patients taking a long-acting benzodiazepine (1.21 odds ratio [OR]), short-acting benzodiazepine (1.16 OR), or nonbenzodiazepine (1.12 OR) had a significantly higher probability of experiencing an accidental event during the first month following treatment initiation compared with patients taking the reference medication $(P<0.05$ for all). A significantly higher probability of experiencing an accidental event was also observed during the 3 -month period following the initiation of treatment (1.62 long-acting benzodiazepine, 1.60 short-acting benzodiazepine, 1.48 nonbenzodiazepine, and 1.56 sedating antidepressant; $P<0.05$ ).

Conclusions: Older adults taking an SAD or any of the benzodiazepine receptor agonists appear to have a greater risk of an accidental event compared with a reference group taking an MR.

Keywords: insomnia, accidental events, benzodiazepine receptor agonist, melatonin receptor agonist, older adults

\section{Introduction}

Insomnia is characterized by inadequate or poor-quality sleep because of difficulty falling asleep (sleep-onset insomnia), difficulty staying asleep (sleep maintenance insomnia), or early morning awakening, and is classified as transient or chronic (Diagnostic and Statistical Manual of Mental Disorders, edition IV, Text Revision). Transient insomnia is common and generally occurs as a result of anxiety, stress, environmental factors (ie, noise, extreme temperatures, change in the surrounding environment), sleep-wake schedule alterations, and medication-related side effects. ${ }^{1}$ Chronic insomnia affects approximately $10 \%$ of the adult population in the US and is more complex, often associated with a combination of comorbid factors, including medical, psychiatric, and sleep disorders. ${ }^{2,3}$

Both types of insomnia are common in older adults, and the prevalence increases with advancing age. ${ }^{3-5}$ Because of changes in sleep architecture, older adults are more likely than younger adults to experience increased nocturnal awakenings, interrupted sleep, and decreased sleep efficiency. ${ }^{6}$ A study by the National Institute of Aging 
of noninstitutionalized older adults indicated that $28 \%$ of respondents had difficulty falling asleep, whereas another $42 \%$ of respondents reported having difficulty falling asleep and staying asleep. ${ }^{7}$

The treatment of insomnia includes both behavioral (eg, cognitive behavioral therapy) and pharmacological therapies (sedating antidepressants, long-acting and short-acting benzodiazepines, nonbenzodiazepine hypnotics, and a selective melatonin receptor agonist). Although benzodiazepines effectively promote sleep, they have a relatively long duration of action, which can be problematic, as the therapeutic action of these medications can extend into the waking hours and cause daytime sedation. ${ }^{8}$ Use of these medications is associated with an increased risk of adverse events such as physical disability, falls, and motor vehicle accidents in older adults. ${ }^{9}$ Studies suggest that older adults who are prescribed a benzodiazepine (either long-acting or short-acting) have an increased risk of falling at least once within 90 days of initiating treatment and are at greater risk for motor vehicle accidents. ${ }^{10,11}$ Nonbenzodiazepine hypnotics are used specifically for the management of insomnia and were developed to reduce the potential for side effects associated with the benzodiazepine medications. ${ }^{12}$ Although each of the nonbenzodiazepine hypnotic medications has a different pharmacokinetic profile, research suggests that falls, fractures, and motor vehicle accidents are also a concern with these medications, with serious economic consequences. ${ }^{13-15}$ Off-label use of sedating antidepressants, particularly trazodone, is also common in the treatment of insomnia. Although studies have supported the efficacy of trazodone in improving sleep in patients with both primary and comorbid insomnia, trazodone can produce sedation, orthostatic hypotension, and blurred vision, all of which increase the risk of falls. ${ }^{16}$ Recent studies suggest that the newest class of insomnia medications, the selective melatonin receptor agonist, has a sleep-promoting action that does not appear to cause balance impairments, rebound insomnia, or next-day cognitive or psychomotor effects that may lead to increased accident risks in older adults. ${ }^{17-20}$

The increased risk of accidental events associated with the use of insomnia medications is particularly troublesome in older adults because they are much more likely to suffer injuries from falls, fractures, and motor vehicle accidents. ${ }^{21-23}$ The use of insomnia medications may compound this risk. However, the assessment of risk is complex and may be confounded by factors associated with untreated insomnia, which by itself has been shown to increase the risks of an accidental event. ${ }^{24,25}$ The goal of the current study was to examine the risk of accidental events in a population of older adults ( $\geq 65$ years of age) prescribed common insomnia medications.

\section{Patients and methods Study design}

A retrospective cohort analysis comparing the risk of accidental events in patients prescribed common insomnia medications was conducted based on the Thomson Medstat MarketScan $^{\circledR}$ 2000-Q2 2006 Medicare Supplemental and Coordination of Benefits databases. These data (representing both the employer-paid and Medicare-paid components of care) include the health insurance claims across the continuum of care (inpatient, outpatient, outpatient pharmacy, and enrollment data) for retirees covered by their previous employer through privately insured fee-for-service, point-ofservice, or capitated health plans. This information comes from administration claims and there is no independent validation of the data using medical charts. However, claim entries are fully adjudicated by the payer, and any data that appear to be erroneous (ie, claims with costs that exceed reasonable limits) are excluded on an individual basis. Cost thresholds for exclusion of claims are in line with what other administration claims databases use, including those used by the Healthcare Cost and Utilization Project, which is developed by the Agency for Healthcare Research and Quality using hospital claims data. Depending on the year, the Medicare supplemental databases include between 2.5 and 3.1 million individuals, and these data are projectable to the US population with Medicare supplemental insurance (12.7 million retirees).

\section{Study population}

Older adults ( $\geq 65$ years) with at least one outpatient pharmaceutical claim for an identified insomnia medication (long-acting benzodiazepine [lorazepam, quazepam, and flurazepam], short-acting benzodiazepine [estazolam, temazepam, and triazolam], nonbenzodiazepine hypnotic [zolpidem, zaleplon, and eszopiclone], sedating antidepressant [trazodone], and selective melatonin receptor agonist [ramelteon]) were included in the analysis. A 12-hour half-life was used as the cutoff between long-acting and short-acting benzodiazepines. Because some of these medications, specifically lorazepam and trazodone, may have multiple indications, only patients with specific doses ( $2 \mathrm{mg}$ or less for lorazepam; $100 \mathrm{mg}$ or less for trazodone) or those taking a certain number of pills supplied per month (no more than 30 pills per month) were selected for study inclusion. 
Patients with injectible formulations of lorazepam were also excluded from the study.

Because insomnia often is not coded on a patient's medical claim, an insomnia diagnosis was not required for study inclusion. If an insomnia diagnosis was present prior to the insomnia medication claim, it was included as a study covariate. The study population was further restricted to those patients who were considered new initiators of insomnia medication therapy (ie, no evidence of a prescription insomnia medication during the 3 -month period prior to study initiation) and who had at least 9 months of health insurance eligibility data (6 months prior to the identification of the first insomnia medication claim and 3 months following the first insomnia medication claim). Patients with evidence of nursing home admissions ( $\mathrm{n}=2526 ; 0.5 \%$ of population), those with insomnia medication polytherapy $(\mathrm{n}=10,672$; $2.0 \%$ of population) during the study period, and Medicare beneficiaries $<65$ years of age $(n=62,571,12.0 \%$ of the population) were excluded from the analysis.

\section{Measurements}

Clinical characteristics in this analysis were measured using the Charlson Comorbidity Index (Deyo adaptation) and the International Classification of Diseases - 9th edition (ICD9-CM) codes from the patients' medical claims data for the 6-month period preceding the initiation of treatment with insomnia medication. Several factors that may contribute to accident risks were assessed because they are meaningful to patients and to the healthcare system. Comorbid disorders that may have affected accident risk were recorded during the study period. These comorbidities included adjustment and stress disorders, alcohol and drug disorders, schizophrenia and other psychotic disorders, seizure disorders, abnormal movements and Parkinsonism disorders, mood disorders, pain disorders, and other mental health disorders. Concomitant medications that may also have affected accident risk were recorded based on the presence of at least one outpatient pharmaceutical claim during the study period. These included anticholinergic/antiparkinsonian/antispastic agents, opiate antagonists, analgesics, antidiabetic agents, antimanic agents, anxiolytics, antidepressants, benzodiazepines, and anticonvulsants (the concomitant antidepressants, benzodiazepines, and anticonvulsant medication groups did not include those used to qualify patients for study inclusion).

The incidence of accidental events was evaluated for two time periods: accidental events occurring during the first 30 days of insomnia therapy and events occurring during the first 3 months of insomnia therapy. Accidental events (falls, fractures, dislocations, sprains/strains, open wounds, intracranial injuries, injuries caused by cutting/piercing instruments, accidents caused by machinery, electrocution, and motor vehicle accidents) were chosen to represent the variety of impairments that may affect daily routines and were identified using External Causes of Injury Codes (based on the International Classification of Diseases) and routine ICD-9-CM codes in the claims files.

\section{Statistics}

Chi-square tests were used for categorical variables, and two-sided $t$ tests were used for continuous variables. The descriptive analysis was performed using SAS (SAS Institute Inc., Cary, NC, USA) version 9.1. The modeled estimations of the probability of accidental events and time to accidental events were performed with Stata (StataCorp, College Station, TX, USA) version 9. To compute the regression-adjusted probability of an accidental event for the two defined time periods, multivariate analyses were conducted using probit models with variable inclusion based on a priori hypotheses. The a priori hypotheses were: 1) patients prescribed a selective melatonin receptor agonist would have a lower risk of an accidental event during the period immediately following the initiation of therapy, and 2) given the presence of an accidental event, the time to such an event would be longer for patients prescribed a selective melatonin receptor agonist.

Probit regression models extend the principles of generalized linear models to better treat the case of dichotomous and categorical variables - in this case, the probability of an accidental event ( 0 if no event and 1 if evidence of an event). Probit is a variant of logit modeling but is based on different data assumptions; specifically, logit analysis is based on log odds, whereas probit uses the cumulative normal probability distribution. These multivariate models included the following covariates: gender, age, Charlson Comorbidity Index, presence of select comorbidities, presence of an insomnia diagnosis, and presence of concomitant medications of interest. Because no accidental events occurred during either the first 30 days or 3 months of insomnia therapy for patients prescribed the reference drug cohort (a selective melatonin receptor agonist), model convergence was not achieved. The existence, finiteness, and uniqueness of maximum likelihood estimates for the probit regression model depend on the pattern of data points in the observation space. If the data are completely or partially separated, it may not be possible to obtain reliable maximum likelihood estimates because convergence may not occur. Model nonconvergence occurs because one or more parameters in the model become 
theoretically infinite - typically because either the model perfectly predicts the response or there are more parameters in the model than can be estimated because the data are sparse. In this particular analysis, model nonconvergence was a direct result of zero observations for the dependent variable of interest for the reference group for the drug cohort variable. In an effort to evaluate the probability of an accidental event within a multivariate framework, a random patient within the selective melatonin receptor agonist cohort was assigned a nonzero value for the dependent variable (presence of an accidental event variable). ${ }^{26}$ This was done in an iterative manner by randomly selecting a patient in the selective melatonin receptor agonist group and assigning them a " 1 " value for the presence of an accidental event. We completed this process numerous times, each time selecting another random patient to be assigned the " 1 " value for the presence of an accidental event and re-running the probit model. Model statistics, coefficients (magnitude and direction) and $P$ values resulted in the same conclusions each time. This data manipulation enabled convergence of the probit regression models and produced interpretable coefficients.

\section{Results \\ Demographics}

The sample used to estimate the probability of an accidental event consisted of 445,329 Medicare patients. A flow-chart describing the derivation of this sample is shown is Figure 1. Demographic and clinical characteristics are shown in Table 1. The majority of patients were prescribed long-acting benzodiazepines and nonbenzodiazepine hypnotics (36.38\% and 35.25\%, respectively). The remaining patients were prescribed shortacting benzodiazepines (18.21\%), a sedating antidepressant $(9.94 \%)$, or a selective melatonin receptor agonist $(0.22 \%)$.

Patients in each cohort except the reference cohort (melatonin receptor agonist) experienced at least one accidental event during the first 30 days of insomnia treatment, and the number of accidental events after 90 days was increased for all cohorts except the melatonin receptor agonist cohort (Table 2). Because

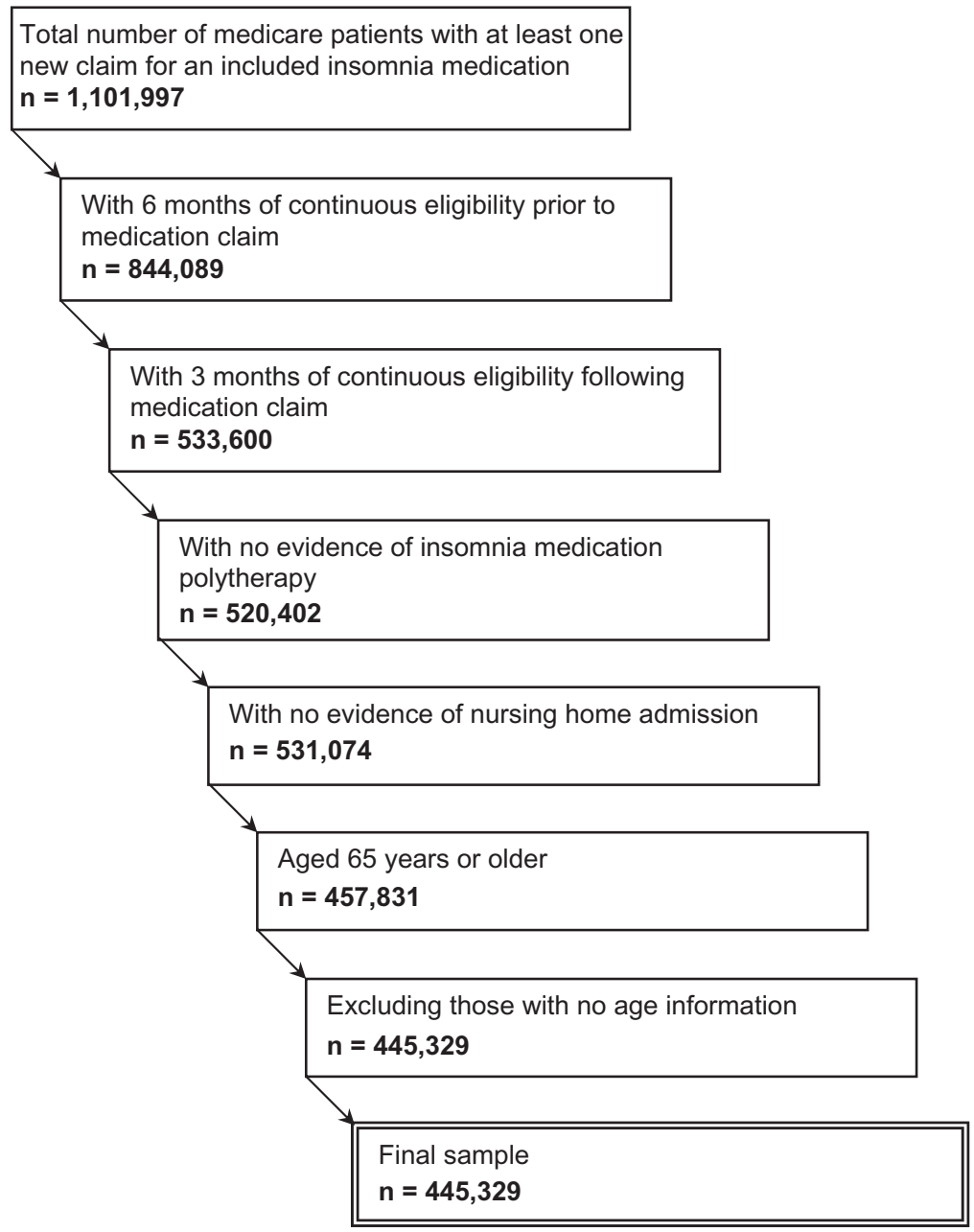

Figure I Flow-chart of the derivation of the sample population. 
patients in the reference cohort experienced no accidental events, the time interval to an event was right censored at 30 days for the first follow-up period and 90 days for the full study.

\section{Probability of an accidental event}

Table 3 shows the results of the probit regressions of the risk of an accidental event during the 30-day and 3-month periods following the initiation of insomnia drug therapy. The probability of an accidental event was significantly greater $(P<0.05)$ at all time points for patients taking a long-acting benzodiazepine, a short-acting benzodiazepine, or a nonbenzodiazepine hypnotic when evaluated against the risk for patients in the reference cohort. Patients taking a sedating antidepressant demonstrated a significantly increased probability of an accidental event only during the 3-month time period. At the end of the study ( 3 months), risks of an accidental event were 1.48 to 1.62 times greater for patients in all evaluated medication cohorts compared with those in the reference cohort. Additional variables that affected the probability of an accidental event are shown in Table 3.

\section{Discussion}

In this study of commonly prescribed hypnotic medications, patients who were prescribed a benzodiazepine, nonbenzodiazepine hypnotic, or sedating antidepressant had significantly higher risks of an accidental event during the 30-day and 3-month periods following pharmacotherapy initiation compared with the reference cohort of a melatonin receptor agonist that had no observed accidental events. Nonbenzodiazepine hypnotics were developed to reduce the potential for side effects associated with the benzodiazepine medications. However, this analysis suggests that the risk of an accidental event is similar among all of the sedating hypnotics.

The trade-off between improved sleep with hypnotic agents and the potential risk of accidents and falls is an ongoing issue for health professionals who treat insomnia in older adults as

Table I Demographic and clinical characteristics of the study population

\begin{tabular}{|c|c|c|c|c|c|}
\hline $\begin{array}{l}\text { Patient } \\
\text { characteristic }\end{array}$ & $\begin{array}{l}\text { Long-acting } \\
\text { benzodiazepine } \\
n=162,015\end{array}$ & $\begin{array}{l}\text { Short-acting } \\
\text { benzodiazepine } \\
n=8 I, 083\end{array}$ & $\begin{array}{l}\text { Nonbenzodiazepine } \\
n=156,987\end{array}$ & $\begin{array}{l}\text { Sedating } \\
\text { antidepressant } \\
n=44,256\end{array}$ & $\begin{array}{l}\text { Melatonin } \\
\text { receptor agonist } \\
\mathbf{n = 9 8 8}\end{array}$ \\
\hline Male, n (\%) & $52,408(32.35)$ & $32,883(40.55)$ & $62,547(39.84)$ & 14,685 (33.18) & $373(37.75)$ \\
\hline Female, n (\%) & $109,607(67.65)$ & $48,200(59.45)$ & $94,440(60.16)$ & $29,57 \mid(66.82)$ & $615(62.25)$ \\
\hline Age, mean (SD) & $75.96(7.28)$ & $76.34(7.17)$ & $75.09(6.96)$ & $75.63(7.34)$ & 75.39 (7.19) \\
\hline Noncapitated insurance plan, n (\%) & $41,418(25.56)$ & $32,558(40.15)$ & $15,510(9.88)$ & I3,047 (29.48) & $36(3.64)$ \\
\hline Capitated insurance plan, n (\%) & $120,597(74.44)$ & $48,525(59.85)$ & |4I,477 (90.12) & $31,209(70.52)$ & $952(96.36)$ \\
\hline Insomnia diagnosis, n (\%) & $527(0.33)$ & $756(0.93)$ & $2,058(1.31)$ & $606(1.37)$ & 77 (7.79) \\
\hline $\begin{array}{l}\text { Charlson Comorbidity Index, } \\
\text { mean (SD) }\end{array}$ & $1.10(2.01)$ & 1.04 ( I.89) & I.2I (2.02) & $0.86(1.66)$ & $1.22(1.80)$ \\
\hline Comorbiditiy, n (\%) & $27,588(17.03)$ & $9,530(11.75)$ & $22,507(14.34)$ & $9,102(20.57)$ & $244(24.70)$ \\
\hline Adjustment disorder and stress & $663(0.4 I)$ & $228(0.28)$ & $417(0.27)$ & $250(0.56)$ & $3(0.30)$ \\
\hline Psychotic disorder & $2,261(1.40)$ & $612(0.75)$ & I,379 (0.88) & $754(1.70)$ & I5 (I.52) \\
\hline Mood disorder & $6,086(3.76)$ & $2,522(3 . I I)$ & $5,527(3.52)$ & $\mathrm{I}, 778(4.02)$ & $32(3.24)$ \\
\hline Anxiety & $2,329(1.44)$ & $801(0.99)$ & 2,023 (1.29) & $722(1.63)$ & $29(2.94)$ \\
\hline Other mental health disorder & $5,248(3.24)$ & I,987 (2.45) & $5,529(3.52)$ & I,389 (3.14) & $46(4.66)$ \\
\hline Alcohol or drug abuse & $5,314(3.28)$ & $1,819(2.24)$ & $4,379(2.79)$ & $2,733(6.18)$ & $88(8.91)$ \\
\hline Seizure disorder & $4,185(2.58)$ & $900(\mathrm{I} . \mathrm{II})$ & $2,206(I .4 I)$ & $\mathrm{I}, 073(2.42)$ & $37(3.74)$ \\
\hline Abnormal movement or & $5,45 \mathrm{I}(3.36)$ & $2,211(2.73)$ & $5,828(3.7 I)$ & I,706 (3.85) & $55(5.57)$ \\
\hline \multicolumn{6}{|l|}{ Parkinsonism disorder } \\
\hline Headache & $7,486(4.62)$ & $\mathrm{I}, 689(2.08)$ & $3,520(2.24)$ & $2,462(5.56)$ & $4 I(4.15)$ \\
\hline Pain & $16,623(10.26)$ & $4,620(5.70)$ & $10,538(6.71)$ & $6,025(13.61)$ & 158 (I5.99) \\
\hline Concomitant medication, n (\%) & 74,805 (46.17) & $36,838(45.43)$ & $84,048(53.54)$ & $21,81 \mathrm{I}(49.28)$ & $671(67.9 I)$ \\
\hline Antihistamines & $12,098(7.47)$ & $5,316(6.56)$ & I5,229 (9.70) & $3,112(7.03)$ & I34 (I3.56) \\
\hline $\begin{array}{l}\text { Anticholinergics/ } \\
\text { antiparkinsonians/antispastics }\end{array}$ & $3,605(2.23)$ & I,380 (I.70) & $3,169(2.02)$ & $848(1.92)$ & $21(2.13)$ \\
\hline Opiate antagonists & $6(0.00)$ & $2(0.00)$ & $7(0.00)$ & $4(0.01)$ & $0(0.00)$ \\
\hline Analgesics & 30,237 (18.66) & $18,013(22.22)$ & 38,844 (24.74) & 7,915 (I7.88) & 276 (27.94) \\
\hline Antidiabetics & I7,428 (I0.76) & 8,915 (10.99) & $20,906(13.32)$ & $4,809(10.87)$ & 158 (I5.99) \\
\hline Antimanic & $337(0.21)$ & $124(0.15)$ & $290(0.18)$ & $112(0.25)$ & $3(0.30)$ \\
\hline Anxiolytic & $3,558(2.20)$ & $\mathrm{I}, 462(\mathrm{I} .80)$ & $3,426(2.18)$ & $\mathrm{I}, 020(2.30)$ & $58(5.87)$ \\
\hline Antidepressants & $28,119(17.36)$ & 10,783 (I3.30) & 27,125 (17.28) & $9,765(22.06)$ & 318 (32.19) \\
\hline Benzodiazepines & $9,161(5.65)$ & $5,857(7.22)$ & I3,904 (8.86) & $3,659(8.27)$ & $129(13.06)$ \\
\hline Anticonvulsants & $9,801(6.05)$ & $4,026(4.97)$ & $10,357(6.60)$ & $3,398(7.68)$ & 155 (15.69) \\
\hline
\end{tabular}

Abbreviation: SD, standard deviation. 
Table 2 Accidental events detected during the 3-month follow-up period after initial prescription

\begin{tabular}{|c|c|c|c|c|c|}
\hline Measurement & $\begin{array}{l}\text { Long-acting } \\
\text { benzodiazepine } \\
n=|62,0| 5\end{array}$ & $\begin{array}{l}\text { Short-acting } \\
\text { benzodiazepine } \\
n=81,083\end{array}$ & $\begin{array}{l}\text { Nonbenzodiazepine } \\
n=156,987\end{array}$ & $\begin{array}{l}\text { Sedating } \\
\text { antidepressant } \\
n=44,256\end{array}$ & $\begin{array}{l}\text { Melatonin } \\
\text { receptor agonist } \\
\mathbf{n}=\mathbf{9 8 8}\end{array}$ \\
\hline \multicolumn{6}{|l|}{ I-month follow-up } \\
\hline $\begin{array}{l}\text { Number of patients with at least } \\
\text { I accidental event, } \mathrm{n}(\%)\end{array}$ & $270(0.17)$ & $114(0.14)$ & $184(0.12)$ & $55(0.12)$ & $0(0.00)$ \\
\hline $\begin{array}{l}\text { Mean time to accidental event, } \\
\text { days (SD) }\end{array}$ & $13.39(9.75)$ & $12.39(9.23)$ & $12.65(9.22)$ & I4.62 (8.99) & NA \\
\hline \multicolumn{6}{|l|}{ 3-month follow-up } \\
\hline $\begin{array}{l}\text { Number of patients with at least } \\
\text { I accidental event, } n(\%)\end{array}$ & $648(0.40)$ & $302(0.37)$ & $440(0.28)$ & I $58(0.36)$ & $0(0.00)$ \\
\hline $\begin{array}{l}\text { Mean time to accidental event, } \\
\text { days (SD) }\end{array}$ & 40.75 (27.39) & $42.90(27.95)$ & $38.81(26.65)$ & $44.02(26.46)$ & NA \\
\hline
\end{tabular}

Abbreviations: NA, not applicable; SD, standard deviation.

well as regulatory agencies. Previous research often focused on nursing home populations or only specific notable events (ie, hip fractures). The earliest evaluations also included agents, such as barbiturates, that are no longer the standard of care. However, a recent review by Glass et al described some rather compelling data associating sedative hypnotics with adverse events in the treatment of insomnia in older adults. ${ }^{11}$ Using a meta-analysis, the authors demonstrate that although sedatives improve sleep quality and amount of sleep, these benefits are outweighed by the associated excessive sleepiness that may put patients at risk for falls, injurious behaviors, and motor vehicle accidents. ${ }^{11}$ The number needed to treat for improved sleep quality was 13 , whereas the number needed to harm for any adverse event was $6 .^{11}$ A key literature review on the treatment of chronic insomnia in geriatric patients determined that long-term use of sedative hypnotics for insomnia lacks an evidence base and identified concerns for potential adverse drug effects, including anterograde amnesia, motor disturbances, excessive daytime sleepiness, and the potential for accidental events. ${ }^{9}$ Further complicating the issue is a recent large retrospective study in Michigan, USA which determined that in elderly nursing-home residents, insomnia, but not hypnotic use, is associated with a greater risk of subsequent falls. ${ }^{24}$ However, the current study used a different patient population that was substantially larger $(\mathrm{N}=445,329)$ and healthier (most patients were free from comorbid conditions with no evidence of nursing home admissions).The endpoints in this study were also broader, including a variety of injuries, than previous assessments of accident risk that mostly focused on falls and fractures. Overall, the current research expands on the results from previous studies and increases the understanding of accident risk associated with the use of hypnotic agents in older adults.

Table 3 Risk factors associated with an accidental event

\begin{tabular}{|c|c|c|c|c|}
\hline \multirow[t]{2}{*}{ Risk factor } & \multicolumn{2}{|c|}{ I-month follow-up period } & \multicolumn{2}{|c|}{ 3-month follow-up period } \\
\hline & Coefficient & Odds ratio $^{a}$ & Coefficient & Odds ratio $^{a}$ \\
\hline Long-acting benzodiazepine treatment ${ }^{\mathrm{b}}$ & 0.1907 & $\mathrm{I} .2 \mathrm{I} *$ & 0.4818 & $1.62 *$ \\
\hline Short-acting benzodiazepine treatment ${ }^{\mathrm{b}}$ & 0.1524 & $1.16 *$ & 0.4704 & $1.60 *$ \\
\hline Nonbenzodiazepine treatment ${ }^{\mathrm{b}}$ & 0.1098 & $1.12^{*}$ & 0.3888 & $1.48^{*}$ \\
\hline Sedating antidepressant treatment ${ }^{\mathrm{b}}$ & 0.1038 & 1.11 & 0.4429 & $1.56 *$ \\
\hline Age & 0.0225 & $1.02 *$ & 0.0221 & $1.02 *$ \\
\hline Female gender & -0.0106 & 0.99 & 0.0032 & 1.00 \\
\hline Insomnia diagnosis (pre-period) & -0.0452 & 0.96 & -0.0243 & 0.98 \\
\hline Charlson Comorbidity Index score (pre-period) & 0.0140 & $1.01 *$ & 0.0131 & $1.0 I^{*}$ \\
\hline Concomitant medication: analgesics & 0.1350 & $1.14^{*}$ & 0.1097 & $1.12^{*}$ \\
\hline Concomitant medication: antidepressants & 0.1040 & $1.11 *$ & 0.1203 & $1.13^{*}$ \\
\hline Concomitant medication: benzodiazepines & 0.0737 & 1.08 & 0.0338 & 1.03 \\
\hline Concomitant medication: anticonvulsants & 0.0622 & 1.06 & 0.0762 & $1.08^{*}$ \\
\hline Comorbidity: alcohol or drug abuse & 0.4089 & $1.5 \mathrm{I}^{*}$ & 0.2764 & $1.32 *$ \\
\hline Comorbidity: seizure disorder & 0.0661 & 1.07 & 0.0849 & $1.09 *$ \\
\hline Comorbidity: abnormal movement/Parkinsonism & 0.1434 & 1.15 & 0.1659 & $1.18^{*}$ \\
\hline Comorbidity: general mental health disorder & 0.2803 & $1.32 *$ & 0.2216 & $1.25 *$ \\
\hline
\end{tabular}

Notes: $* P<0.05$; ${ }^{\circ}$ Odds ratios compare the risk of accidental event for the listed variable relative to its specific reference group while controlling for all the other variables in the model; ${ }^{b}$ Risk of an accidental event for the medication cohorts was compared with the reference cohort (melatonin receptor agonist). 
There are several studies of accident rates both in the general population and in those with insomnia. For example, according to the National Center for Injury Prevention and Control, the rate of unintentional nonfatal injuries in the United States between 2001 and 2007 was 9305 per 100,000 people (0.093). ${ }^{27}$ When the data were restricted to those $>65$ years, the rate was 7852.52 per 100,000 people (0.079). ${ }^{27}$ Accident rates in people with untreated insomnia vary between studies but most show an increase in accidents among those with insomnia. In a Japanese study, data from 2903 workers between the ages of 16 and 83 years showed that insomnia symptoms were associated with an adjusted odds ratio of 1.3 for the occurrence of occupational injuries. ${ }^{28}$ A study by Balter and Uhlenhuth in the US population showed that past-year prevalence rates for serious accidents/ injuries in subjects with chronic untreated insomnia were 4.5 times higher than normal controls ( $9 \%$ and $2 \%$, respectively). ${ }^{25}$ These findings are similar to a French study that showed patients with severe insomnia were more likely than good sleepers to experience work-related accidents over a 12-month time period ( $8 \%$ and $1 \%$, respectively). ${ }^{29}$ In this study, the range of accident rates for older adults ( 0.28 to 0.40$)$ was greater than that in the general population (0.079), but that may have been due to several factors and not simply the presence of insomnia or hypnotics. In subjects of all ages with untreated insomnia, the rate of accidents is much higher than in normal controls. ${ }^{25,28,29}$ It is possible that the accident rates in this study, although higher than those in the overall population, may actually have been reduced compared with the potential accident rates if the patients had not been treated for insomnia.

Several limitations of the data and these analyses should be noted. First, the presence of insomnia was identified by prescription records only. Although the prescription hypnotic medications captured in this study are consistent with those of other published studies, it is not possible to confirm that these medications were indeed used for insomnia treatment. We attempted to mitigate this possibility by eliminating doses that may be used for other conditions (ie, trazodone at doses $>100 \mathrm{mg}$ for depression treatment). Second, there was no control group of untreated insomniacs, which may have affected the analysis due to the risk of accidental events associated with insomnia itself. It is possible that, in this study, all of the hypnotics reduced the overall accident rate associated with untreated insomnia. An overview of the accident rates in the population with and without insomnia has been provided as a comparison with the rates found in this study. Third, the results of this study should be viewed in light of limitations that are inherent in retrospective claims data analysis. Correct categorization of insurance database information depends on correct coding by clinicians and other medical staff. The accuracy of diagnostic coding cannot be evaluated in a claims-based study. Patients may also receive treatment that is not submitted to their health plan for reimbursement and thus not included in claims data. Also, consideration of the methodology used to ensure that model convergence was achieved should be taken into account when evaluating the risk of accidental events. Finally, this analysis included claims data from 2000 through the second quarter of 2006, but ramelteon was not approved until 2005, which limits the number of patients and the amount of data available for comparison with the other medication classes. It is possible that there may have been a time trend bias in the analysis. However, this would occur only if the risks for an accidental event had changed over the years for the other medications included in the analysis. Also, if accidental events were more differentially reported prior to 2005, the risk assessments may have been altered, but this seems unlikely.

The small number of patients taking a melatonin receptor agonist (compared with the other drug cohorts) does make it difficult to draw definitive conclusions from this study. The small sample size may have contributed to the lack of an accidental event in the melatonin receptor agonist cohort. However, model convergence was used to adjust for the lack of an event, and the small sample size was accounted for in the statistical analyses. For these reasons, the melatonin receptor agonist cohort was used as a reference for comparison with the other medication cohorts, and no specific conclusions were drawn relating to the melatonin receptor agonist (or between any of the cohorts). In the future, additional studies with a greater number of subjects receiving melatonin receptor agonists may be needed to determine how to most appropriately use hypnotics in older adults, both to treat insomnia successfully and to reduce the risks of accidental events.

Although more work is warranted to evaluate whether these findings can be supported in other patient populations, these results are nevertheless important. Results of this study add to the literature on the risk of accidental events in patients who are taking insomnia medications. Finally, although the sample size was small, the data in this retrospective claims analysis support findings from double-blind, placebo-controlled studies that indicate that selective melatonin receptor agonists lack the apparent drug-related or residual effects that can lead to accidental events, making the case for more selectively targeted treatments for insomnia. ${ }^{17,19,30,31}$

\section{Conclusions}

Older adults taking a sedating antidepressant or any of the benzodiazepine receptor agonists appear to have a greater 
risk of an accidental event compared with a reference group taking a selective melatonin receptor agonist.

\section{Acknowledgment}

This study was supported by funding from the Takeda Pharmaceutical Company, Ltd. Assistance with manuscript writing and editing was provided by Sara Sarkey, PhD, an employee of Takeda Pharmaceuticals North America.

\section{Disclosure}

Financial support for this study was provided by the Takeda Pharmaceutical Company, Ltd. Justin Doan and Bob Baran were employees of Takeda Global Research and Development when this study was performed. Alon Avidan has acted as a consultant and speaker for the Takeda Pharmaceutical Company and has participated as a speaker for Sepracor, Pfizer, and Cephalon. Liisa Palmer has acted as a consultant for the Takeda Pharmaceutical Company and is an employee of Thomson Reuters, whose staff analyzed the data.

\section{References}

1. Roehrs T, Zorick F, Roth T. Transient and short-term insomnias. In: Kryger M, Roth T, Dement WC, eds. Principles and Practice of Sleep Medicine. 3rd edition Philadelphia, PA: W.B. Saunders and Company; 2000:624-632.

2. Roth T, Roehrs T. Insomnia: epidemiology, characteristics, and consequences. Clin Cornerstone. 2003;5:5-15.

3. Mellinger GD, Balter MB, Uhlenhuth EH. Insomnia and its treatment. Prevalence and correlates. Arch Gen Psychiatry. 1985;42:225-232.

4. Foley D, Ancoli-Israel S, Britz P, Walsh J. Sleep disturbances and chronic disease in older adults: results of the 2003 National Sleep Foundation Sleep in America Survey. J Psychosom Res. 2004;56:497-502.

5. Ancoli-Israel S. Insomnia in the elderly: a review for the primary care practitioner. Sleep. 2000;23 Suppl 1:S23-S30.

6. Folks DG, Burke WJ. Psychotherapeutic agents in older adults. Sedative hypnotics and sleep. Clin Geriatr Med. 1998;14:67-86.

7. Foley DJ, Monjan AA, Brown SL, Simonsick EM, Wallace RB, Blazer DG. Sleep complaints among elderly persons: an epidemiologic study of three communities. Sleep. 1995;18:425-432.

8. Erman MK. Therapeutic options in the treatment of insomnia. J Clin Psychiatry. 2005;66 Suppl 9:18-23.

9. Bain KT. Management of chronic insomnia in elderly persons. Am J Geriatr Pharmacother. 2006;4:168-192.

10. Landi F, Onder G, Cesari M, Barillaro C, Russo A, Bernabei R. Psychotropic medications and risk for falls among community-dwelling frail older people: an observational study. J Gerontol A Biol Sci Med Sci. 2005;60:622-626.

11. Glass J, Lanctot K, Herrmann N, Sproule B, Busto U. Sedative hypnotics in older people with insomnia: meta-analysis of risks and benefits. BMJ. 2005;331:1169-1173.

Drug, Healthcare and Patient Safety

\section{Publish your work in this journal}

Drug, Healthcare and Patient Safety is an international, peer-reviewed open-access journal exploring patient safety issues in the healthcare continuum from diagnostic and screening interventions through to treatment, drug therapy and surgery. The journal is characterized by the rapid reporting of reviews, original research, clinical, epidemiological and
12. Terzano MG, Rossi M, Palomba V, Smerieri A, Parrino L. New drugs for insomnia: comparative tolerability of zopiclone, zolpidem and zaleplon. Drug Saf. 2003;26:261-282.

13. Verster JC, Veldhuijzen DS, Volkerts ER. Residual effects of sleep medication on driving ability. Sleep Med Rev. 2004;8:309-325.

14. Wang PS, Bohn RL, Glynn RJ, Mogun H, Avorn J. Zolpidem use and hip fractures in older people. J Am Geriatr Soc. 2001;49:1685-1690.

15. Menzin J, Lang KM, Levy P, Levy E. A general model of the effects of sleep medications on the risk and cost of motor vehicle accidents and its application to France. Pharmacoeconomics. 2001;19:69-78.

16. Benca RM. Diagnosis and treatment of chronic insomnia: a review. Psychiatr Serv. 2005;56:332-343.

17. Erman M, Seiden D, Zammit G, Sainati S, Zhang J. An efficacy, safety, and dose-response study of ramelteon in patients with chronic primary insomnia. Sleep Med. 2006;7:17-24.

18. Borja NL, Daniel KL. Ramelteon for the treatment of insomnia. Clin Ther. 2006;28:1540-1555.

19. Zammit G, Wang-Weigand S, Rosenthal M, Peng X. Effect of ramelteon on middle-of-the-night balance in older adults with chronic insomnia. J Clin Sleep Med. 2009;5:34-40.

20. Johnson MW, Suess PE, Griffiths RR. Ramelteon: a novel hypnotic lacking abuse liability and sedative adverse effects. Arch Gen Psychiatry. 2006;63:1149-1157.

21. Binder S. Injuries among older adults: the challenge of optimizing safety and minimizing unintended consequences. Inj Prev. 2002;8:IV2-IV4.

22. Aschkenasy MT, Rothenhaus TC. Trauma and falls in the elderly. Emerg Med Clin North Am. 2006;24:413-432.

23. Braver ER, Trempel RE. Are older drivers actually at higher risk of involvement in collisions resulting in deaths or non-fatal injuries among their passengers and other road users? Inj Prev. 2004;10:27-32.

24. Avidan AY, Fries B, James M, Szafara K, Wright G, Chervin R. Insomnia and hypnotic use, recorded in the minimum data set, as predictors of falls and hip fractures in Michigan nursing homes. J Am Geriatr Soc. 2005;53:955-962.

25. Balter MB, Uhlenhuth EH. New epidemiologic findings about insomnia and its treatment. J Clin Psychiatry. 1992;53 Suppl:34-39.

26. Cappellari L, Jenkins SP. Calculation of Multivariate Normal Probabilities By Simulation, With Applications to Maximum Simulated Likelihood Estimation. Available from: http://ssrn.com/abstract=900829. SSRN eLibrary. Published 2006 Accessed 2010 October 22.

27. WISQARS Nonfatal Injury Report. Available from: http://webappa. cdc.gov/sasweb/ncipc/nfirates2001.html. National Center for Injury Prevention and Control. Published 2009. Accessed 2010 October 22.

28. Nakata A, Ikeda T, Takahashi M, et al. Sleep-related risk of occupational injuries in Japanese small and medium-scale enterprises. Ind Health. 2005;43:89-97.

29. Leger D, Guilleminault C, Bader G, Levy E, Paillard M. Medical and socio-professional impact of insomnia. Sleep. 2002;25:625-629.

30. Zammit G, Erman M, Wang-Weigand S, Sainati S, Zhang J, Roth T. Evaluation of the efficacy and safety of ramelteon in subjects with chronic insomnia. J Clin Sleep Med. 2007;3:495-504.

31. Roth T, Seiden D, Wang-Weigand S, Zhang J. A 2-night, 3-period, crossover study of ramelteon's efficacy and safety in older adults with chronic insomnia. Curr Med Res Opin. 2007;23:1005-1014.

post-marketing surveillance studies, risk management, health literacy and educational programs across all areas of healthcare delivery. The manuscript management system is completely online and includes a very quick and fair peer-review system. Visit http://www.dovepress.com/ testimonials.php to read real quotes from published authors. 